\title{
Mucoepidermoid carcinoma of parotid gland and membranous nephropathy - differentiation between sclerosing mucoepidermoid carcinoma with eosinophilia and Kimura's disease
}

\author{
Hayato Fujioka', Tsutomu Koike ${ }^{1}$, Teruhiko Imamura ${ }^{1 *}$ (D), Kota Kakeshita ${ }^{1}$, Hidenori Yamazaki ${ }^{1}$, Hideharu Abe ${ }^{2}$, \\ Takahiko Nakajima $^{3}$ and Koichiro Kinugawa ${ }^{1}$
}

\begin{abstract}
Background: When we encounter patients who present with both a neck mass and nephrotic syndrome, both malignancy and Kimura's disease need to be evaluated as the therapeutic strategies differ vastly between them.

Case presentation: We present the case of a 27 -year-old male patient with neck mass and nephrotic syndrome. The presence of both eosinophilia and elevated immunoglobulin E levels were concerning for Kimura's disease, which is an allergic syndrome defined by eosinophilic granulomas of neck soft tissue along with peripheral eosinophilia. The eventual final diagnosis, however, was sclerosing mucoepidermoid carcinoma of parotid gland with both eosinophilia and membranous nephropathy. Following the surgical resection of the mass, the nephrotic syndrome completely resolved.
\end{abstract}

Conclusion: Detailed histopathological assessments of both the parotid gland and renal tissue were key aspects of the diagnosis and management to exclude Kimura's disease.

Keywords: Membranous nephropathy, Nephrotic syndrome, Sclerosing mucoepidermoid carcinoma with eosinophilia

\section{Background}

Membranous nephropathy can occur in the setting of malignant tumors, and often recovers following definitive treatment of malignancy [1]. Sclerosing mucoepidermoid carcinoma with eosinophilia is a rare variant of mucoepidermoid carcinoma, for which surgical resection is generally recommended as a primary treatment. There are currently no published reports of nephrotic syndrome associated with mucoepidermoid carcinoma. Kimura's

\footnotetext{
* Correspondence: teimamu@med.u-toyama.ac.jp

'The Second Department of Internal Medicine, University of Toyama, 2630 Sugitani, Toyama, Toyama 930-0194, Japan

Full list of author information is available at the end of the article
}

disease, which is a benign syndrome accompanied by eosinophilic granulomas of neck soft tissue often found in young men of east-Asian descent, sometimes accompanies renal disease and can be treated by steroid therapy $[2,3]$.

We present here a young male patient who suffered mucoepidermoid carcinoma of right parotid grand with localized spread to lymph nodes and secondary membranous nephropathy, both of which had significant eosinophilic infiltration. The presence of peripheral eosinophilia and elevated immunoglobulin E level has a broad differential diagnosis, with vastly different treatment pathways.

(c) The Author(s). 2020 Open Access This article is licensed under a Creative Commons Attribution 4.0 International License, which permits use, sharing, adaptation, distribution and reproduction in any medium or format, as long as you give appropriate credit to the original author(s) and the source, provide a link to the Creative Commons licence, and indicate if changes were made. The images or other third party material in this article are included in the article's Creative Commons licence, unless indicated otherwise in a credit line to the material. If material is not included in the article's Creative Commons licence and your intended use is not permitted by statutory regulation or exceeds the permitted use, you will need to obtain permission directly from the copyright holder. To view a copy of this licence, visit http://creativecommons.org/licenses/by/4.0/ The Creative Commons Public Domain Dedication waiver (http://creativecommons.org/publicdomain/zero/1.0/) applies to the data made available in this article, unless otherwise stated in a credit line to the data. 


\section{Case presentation}

A 27-year-old Japanese male patient without a history of any allergic syndromes was admitted to our institute with bilateral peripheral edema, proteinuria, and swelling of the right parotid gland. Cytology of the parotid gland and lymph node biopsy showed no malignancy, though eosinophilic infiltration in the lymph node was observed. He was diagnosed with nephrotic syndrome with $11.9 \mathrm{~g} /$ $\mathrm{g}$ of creatinine of proteinuria, $1.2 \mathrm{~g} / \mathrm{dL}$ of serum albumin, and $420 \mathrm{mg} / \mathrm{dL}$ of low-density lipoprotein. Mild peripheral eosinophilia $(790 / \mu \mathrm{L})$ and elevated immunoglobulin E $(6896 \mathrm{IU} / \mathrm{mL})$ were also present. Immunoglobulin G was $294 \mathrm{mg} / \mathrm{dL}$, soluble interleukin 2 receptor was 457 $\mathrm{U} / \mathrm{mL}, \mathrm{C} 3$ was $102.9 \mathrm{mg} / \mathrm{dL}, \mathrm{C} 4$ was $43.1 \mathrm{mg} / \mathrm{dL}$, and total complement activity was $39 \mathrm{U} / \mathrm{mL}$.

Kidney sizes were $112 \mathrm{~mm}$ (right) and $119 \mathrm{~mm}$ (left). We performed a kidney biopsy to further investigate the mechanism of the observed nephrotic syndrome. On light microscopy, the glomerular basement membrane exhibited mild diffuse thickening with spike formation (Fig. 1a). Eosinophilic interstitial infiltration was also seen (Fig. 1b). Immunofluorescence staining showed diffuse granular deposits of immunoglobulin $\mathrm{G}$ and $\mathrm{C} 3$ along the glomerular capillary walls (Fig. 1c). Immunoglobulin G4 was not predominant for immunoglobulin $G$ subclass, and kappa and lambda light chains had equal intensity in the immunofluorescence staining. Immunofluorescence staining for the phospholipase A2 receptor (PLA2R) and the thrombospondin type 1 domain-containing 7A (THSD7A) were negative. The electron microscopy showed global subepithelial electron-dense deposits and spike formation of the glomerular baseline membrane (Fig. 1d). He was diagnosed with stage II secondary membranous nephropathy.

Computed tomography showed a $40 \mathrm{~mm}$ of tumor in the right parotid grand, accompanied by a $23 \mathrm{~mm}$ lymphoid focus (Fig. 2), both of which showed uptake by fluorodeoxyglucose-position emission tomography. We at this point suspected malignant disease, instead of an alternative benign presentation such as Kimura's disease. Repeat biopsies eventually demonstrated carcinoma and lymph node metastasis (T3N2M0, stage IVa).

Before surgical excision, steroid pulse therapy (methylprednisolone $500 \mathrm{mg} \times 3$ days) was performed, leading to the partial reduction of proteinuria and eosinophilia. At one month following pulse therapy, the patient underwent successful right parotidectomy with neck dissection. The resected specimen was consistent with the diagnosis of sclerosing mucoepidermoid carcinoma with eosinophilia, a variant of mucoepidermoid carcinoma (pT3N2b) (Fig. 3). The proteinuria achieved complete remission and eosinophilia normalized without steroid therapy during the 12-month follow-up with concomitant post-operative radiation therapy (60 Gy /30fr). He has had no recurrence of disease over two-year follow-up.

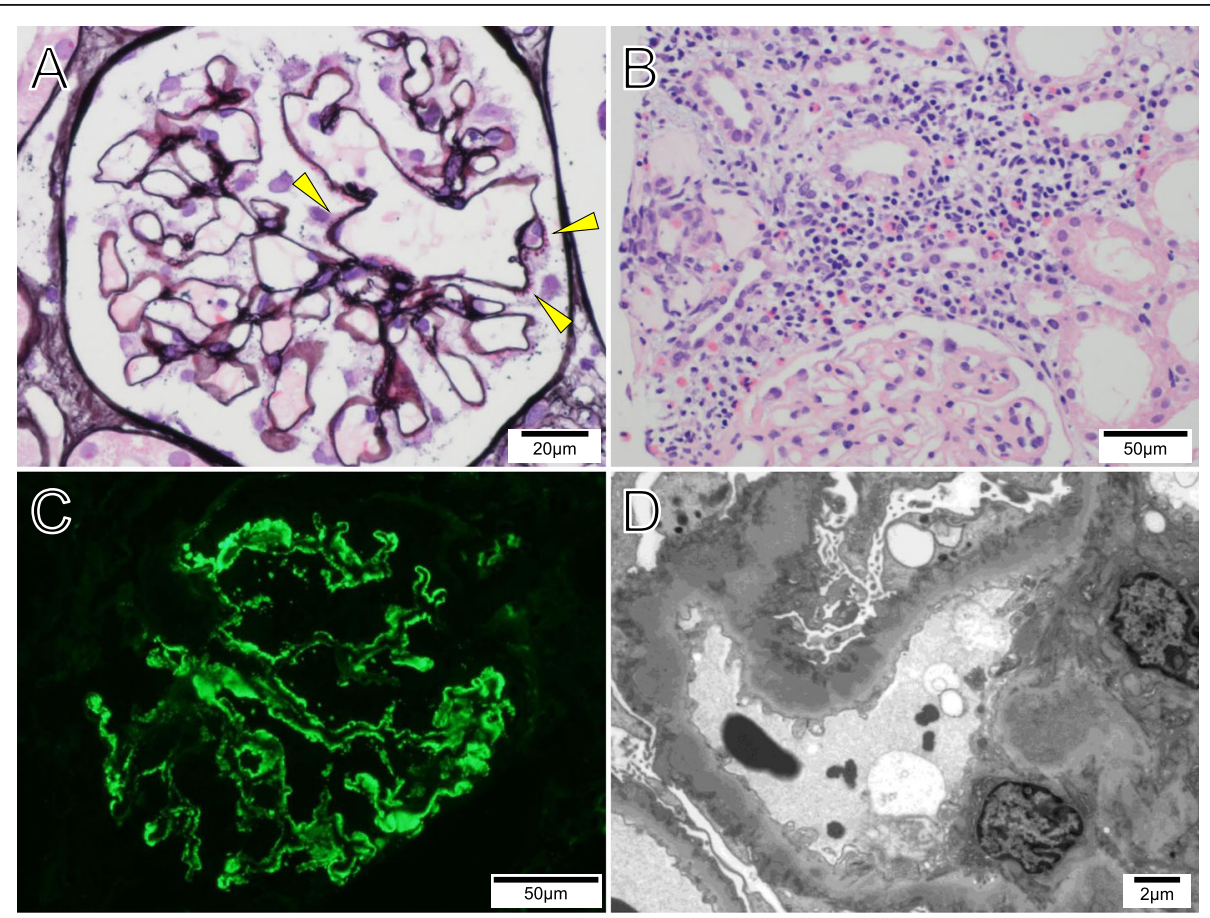

Fig. 1 Histopathological findings in kidney biopsy specimen. a Diffuse thickness of the glomerular basement membrane with spike formation (arrowhead) (Periodic acid-methenamin-silver stain). b Infiltration of eosinophils in renal interstitium (Hematoxylin-Eosin stain). c Diffuse granular deposits of immunoglobulin $\mathrm{G}$ along the glomerular capillary walls (immunofluorescence stain for $\operatorname{lgG}$ ). $\mathbf{d}$ Global subepithelial electron-dense deposits and spike formation of the glomerular baseline membrane (electron microscopy) 


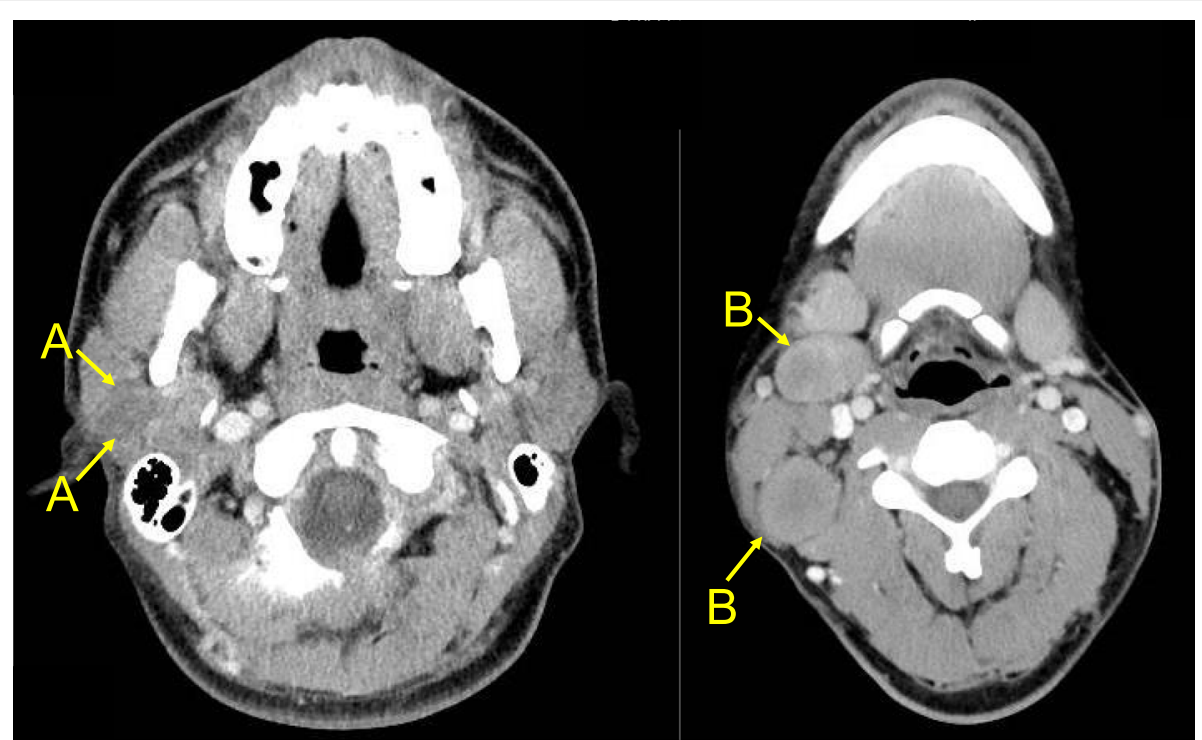

Fig. 2 Head computed tomography shows tumor at right parotid gland (a) and lymphadenopathy of right neck (b)

\section{Discussion and conclusion}

We diagnosed mucoepidermoid carcinoma with eosinophilia and excluded Kimura's disease with successive biopsies and detailed histopathological assessment. The patient did clinically well following careful exclusion of Kimura's disease, for which the correct therapeutic pathway was surgical resection instead of steroid therapy.
Both Kimura's disease and mucoepidermoid carcinoma with eosinophila have several common characteristics, including neck mass with lymph node enlargement, eosinophilia, and high serum immunoglobulin E level.

Mucoepidermoid carcinoma is the most common malignancy among salivary gland-origin tumors, and although rare, it can occur in younger patients [4].

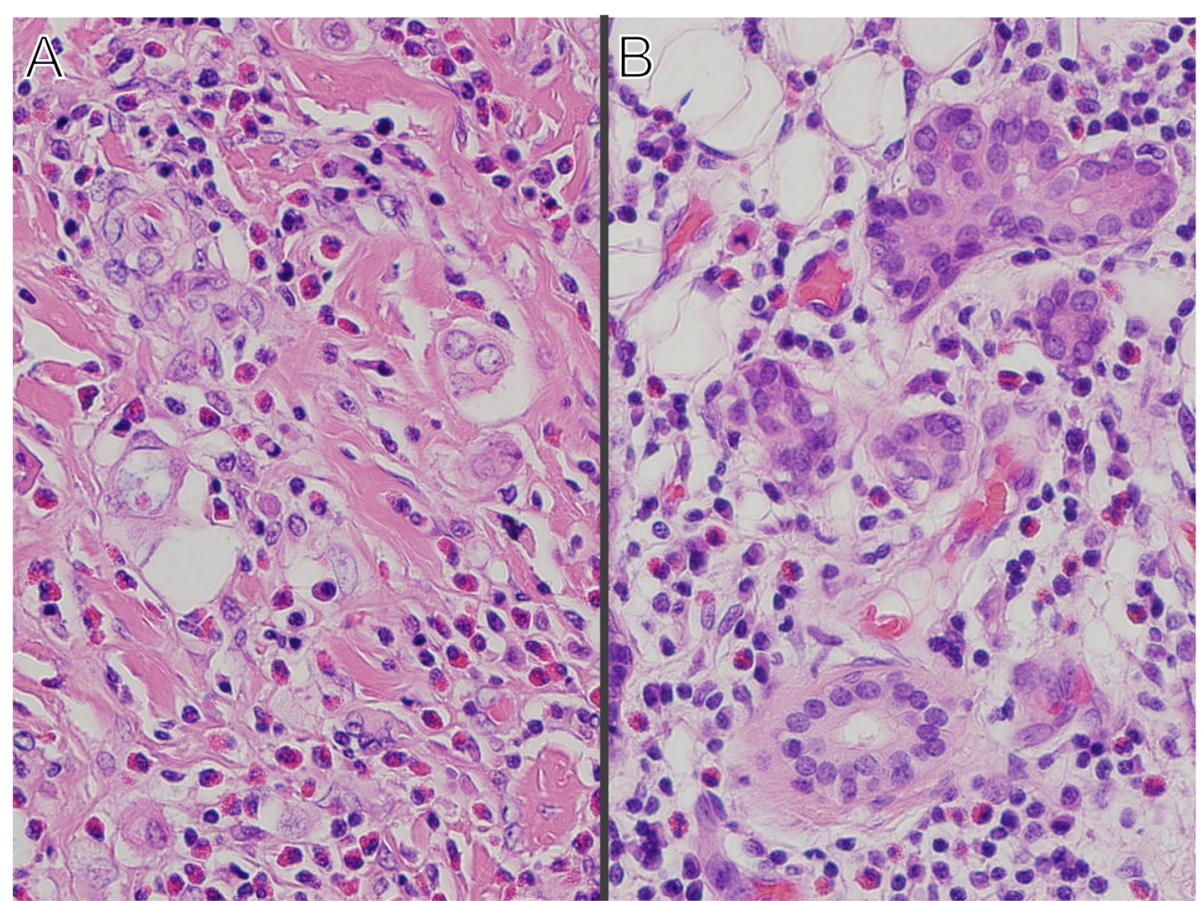

Fig. 3 a Tumor of right parotid gland (Hematoxylin-Eosin stain) showing invasion of tumor cells, surrounded by sclerotic stroma and numerous eosinophils. b Normal tissue of right parotid gland (Hematoxylin-Eosin stain) also showing infiltration of eosinophil 
Mucoepidermoid carcinoma has several variants. Sclerosing mucoepidermoid carcinoma with eosinophilia is one of more rarely encountered variants [5]. The exact mechanism of why this carcinoma is associated with peripheral eosinophilia and infiltration is uncertain. Prior studies have suggested that tumor-derived cytokine release might be an important pathobiological mechanism [6-8].

Kimura's disease is a rare syndrome accompanied by eosinophilic granulomas of neck soft tissue, peripheral eosinophilia, and high immunoglobulin E level. It is most often observed in young East-Asian males [2, 3]. This is a benign chronic granulomatous disease characterized by follicular lymphomas with eosinophilic infiltration. The disease can be treated by steroids or other forms of systemic immunosuppression [9]. Prior reports suggest that renal disease with nephrotic syndrome may occur in up to $16 \%$ of patients with Kimura's disease [10].

The pathogenesis of Kimura's disease remains unknown. Trauma, infection, an immunoglobulin E-mediated hypersensitivity reaction, or an autoimmune process might stimulate cytokine release that stimulates eosinophil production [11]. Of note, there are no published reports of Kimura's disease in the presence of a confounding malignancy. In this case, atypical change with eosinophilic interstitial infiltration and negative expression of PLA2R and THSD7A on renal biopsy suggested secondary membranous nephropathy instead of a de novo origin [12].

To our knowledge, this is the first published report of mucoepidermoid carcinoma associated with membranous nephropathy. It is well known that patients with malignancies may have secondary membranous nephropathy (522\%) [1]. Cases have been reported in lung, prostate and colon cancers, and even with hematologic malignancies [13]. The mechanism of why malignancy-related secondary membranous nephropathies can occur remains unknown, but several hypotheses are proposed [14]: (1) antibody stimulation from tumor antigens immunologically similar to an endogenous podocyte antigen, leading to in situ immune complex formations; (2) shed tumor antigens might form circulating immune complexes that are subsequently trapped in the glomerular capillary wall; (3) circulating antibodies might also react to the tumor antigens that have already been planted in the subepithelial location; and (4) an extrinsic process including viral infection or underlying abnormal immune response might be responsible for both diseases. In this case, a tumor-associated immunoreaction might have had a considerable impact on the development of a secondary membranous nephropathy. The detailed mechanism of renal interstitial infiltration of eosinophils continues to remain uncertain, though tumor-secreted cytokine release might be the causative pathway.

\section{Abbreviations}

PLA2R: Phospholipase A2 receptor; THSD7A: Thrombospondin type 1 domain-containing $7 \mathrm{~A}$

\section{Acknowledgements}

Not applicable.

\section{Authors' contributions}

HF contributed to analyzing and interpretation of data and writing the manuscript. TK contributed to interpretation of data and writing the manuscript. TI contributed to interpretation of data and writing the manuscript. KKa contributed to analyzing and interpretation of data and writing the manuscript. HY contributed to managing the patient and assessing the data. HA contributed to managing the patient and operation TN contributed to analyzing and interpretation of pathological findings. KKi contributed to analyzing and interpretation of data and writing the manuscript. The authors read and approved the final manuscript.

Funding

There was no funding.

Availability of data and materials

All the date supporting our findings is contained within the manuscript.

Ethics approval and consent to participate

The case report was approved by the Medical Ethics Committee of the University of Toyama. The patient provided written informed consent for participation in the study at University of Toyama.

\section{Consent for publication}

The patient received all information regarding this case report. Written informed consent for publication in BMC Nephrology was obtained from the patient.

\section{Competing interests}

The authors declare that they have no competing interests.

\section{Author details}

${ }^{1}$ The Second Department of Internal Medicine, University of Toyama, 2630 Sugitani, Toyama, Toyama 930-0194, Japan. ²Department of

Otorhinolaryngology, Head \& Neck Surgery, University of Toyama, Toyama, Japan. ${ }^{3}$ Department of Diagnostic Pathology, University of Toyama, Toyama, Japan.

Received: 15 December 2019 Accepted: 19 August 2020

Published online: 26 August 2020

\section{References}

1. Row PG, Cameron JS, Turner DR, Evans DJ, White RH, Ogg CS, et al. Membranous nephropathy. Long-term follow-up and association with neoplasia. Q J Med. 1975;44(174):207-39.

2. Kimura T. On the unusual granulation combined with hyperplastic changes of lymphatic tissue. Trans Soc Pathol Jpn. 1948;37(2):179-80.

3. Kuo $\Pi$, Shih LY, Chan HL. Kimura's disease. Involvement of regional lymph nodes and distinction from angiolymphoid hyperplasia with eosinophilia. Am J Surg Pathol. 1988;12(11):843-54.

4. Guevara-Canales JO, Morales-Vadillo R, Guzmán-Arias G, Cava-Vergiú CE, Guerra-Miller H, Montes-Gil JE. Mucoepidermoid carcinoma of the salivary glands. A retrospective study of 51 cases and review of the literature. Acta Odontol Latinoam. 2016;29(3):230-8.

5. Urano M, Abe M, Horibe $Y$, Kuroda M, Mizoguchi $Y$, Sakurai $K$, et al. Sclerosing mucoepidermoid carcinoma with eosinophilia of the salivary glands. Pathol Res Pract. 2002;198(4):305-10.

6. Hu G, Wang S, Zhong K, et al. Tumor-associated tissue eosinophilia predicts favorable clinical outcome in solid tumors: a meta-analysis. BMC Cancer. 2020;20(1):454

7. Gatault S, Legrand F, Delbeke M, Loiseau S, Capron M. Involvement of eosinophils in the anti-tumor response. Cancer Immunol Immunother. 2012; 61(9):1527-34

8. Anagnostopoulos GK, Sakorafas GH, Kostopoulos P, et al. Disseminated colon cancer with severe peripheral blood eosinophilia and elevated serum levels of interleukine-2, interleukine-3, interleukine-5, and GM-CSF. J Surg Oncol. 2005;89(4):273-5. 
9. Natov SN, Strom JA, Ucci A. Relapsing nephrotic syndrome in a patient with Kimura's disease and IgA glomerulonephritis. Nephrol Dial Transplant. 1998; 13(9):2358-63.

10. Yamada A, Mitsuhashi K, Miyakawa Y. Membranous glomerulonephritis associated with eosinophilic lymphfolliculosis of the skin: report of a case and review of literature. Clin Nephrol. 1982;18:211-5.

11. Terada N, Konno A, Shirotori K, Fujisawa T, Atsuta J, Ichimi R, et al. Mechanism of eosinophil infiltration in the patient with subcutaneous angioblastic lymphoid hyperplasia with eosinophilia (Kimura's disease). Mechanism of eosinophil chemotaxis mediated by candida antigen and IL5. Int Arch Allergy Immunol. 1994;104 Suppl 1(1):18-20.

12. Couser WG. Primary membranous nephropathy. Clin J Am Soc Nephrol. 2017;12(6):983-97.

13. Leeaphorn N, Kue APP, Thamcharoen N, Ungprasert P, Stokes MB, Knight EL. Prevalence of cancer in membranous nephropathy: a systematic review and meta-analysis of observational studies. Am J Nephrol. 2014;40(1):29-35.

14. Beck LH Jr. Membranous nephropathy and malignancy. Semin Nephrol. 2010;30(6):635-44.

\section{Publisher's Note}

Springer Nature remains neutral with regard to jurisdictional claims in published maps and institutional affiliations.

Ready to submit your research? Choose BMC and benefit from:

- fast, convenient online submission

- thorough peer review by experienced researchers in your field

- rapid publication on acceptance

- support for research data, including large and complex data types

- gold Open Access which fosters wider collaboration and increased citations

- maximum visibility for your research: over $100 \mathrm{M}$ website views per year

At BMC, research is always in progress.

Learn more biomedcentral.com/submissions 